\title{
Interstitial deletion of the distal long arm of chromosome 4
}

\author{
P Sarda, G Lefort, J P Fryns, C Humeau, D Rieu
}

\begin{abstract}
We report the first case of an interstitial deletion of the distal long arm of chromosome $4($ q31.22 $\rightarrow$ q34.2). The major clinical features are described and compared to those of other published reports of del 4q, mainly those sharing a common deleted segment with the present case (both interstitial and terminal). This comparison suggests that the characteristic phenotype attributed to terminal deletions of 4 q31 $\rightarrow$ qter probably mainly results from loss of the segment q31 $\rightarrow$ q33-34.
\end{abstract}

\section{Department of}

Pediatrics and

Medical Genetics,

University of

Montpellier, Hôpital

Saint-Charles,

Montpellier, France.

P Sarda

D Rieu

\section{Cytogenetics}

Laboratory,

University of

Montpellier, Hôpital

Saint-Charles,

Montpellier, France.

G Lefort

C Humeau

Centre for Human

Genetics, University

Hospital, Leuven,

Belgium.

J P Fryns

Correspondence to $\mathrm{Dr}$ Sarda, Service de Pédiatrie II, Hôpital Saint-Charles, 34059 Montpellier, France.

Received 7 May 1991

Revised version accepted

1 October 1991.
A review of published reports shows that interstitial deletions of the distal long arm of chromosome 4 are rare. ${ }^{12}$ We report a new case of an interstitial deletion in a female infant with physical characteristics resembling those encountered in terminal $4 \mathrm{q} 31$ deletions. ${ }^{34}$

\section{Case report}

The proband was born to a gravida 8 , para 8 mother. To our knowledge the other sibs are normal. At the end of a poorly monitored pregnancy marked by maternal alcohol abuse the child was born at term by spontaneous vaginal delivery. Birth weight was $2700 \mathrm{~g}$, length $46 \mathrm{~cm}$ ( $<3$ rd centile), and head circumference $32 \mathrm{~cm}$ (10th centile). The Apgar score was 0 necessitating tracheal intubation and transfer to the neonatal intensive care unit; assisted ventilation was necessary for 10 days owing to meconium aspiration.

The major physical finding needing urgent surgery was a cardiac defect, consisting of coarctation of the aorta and an interventricular communication. In addition, ultrasound scan of the kidneys detected a duplication of the left collecting system and skeletal radiographs showed bilateral hypoplastic first ribs and fusion of the second and third lumbar vertebrae.

All other internal organs, particularly the brain, appeared normal. Cardiac surgery was immediately instigated and by the end of the first month the heart defect was completely corrected.

At the age of 18 months postnatal growth failure was evident: weight was $8.5 \mathrm{~kg}$ $(<2 \mathrm{SD})$, height $71 \mathrm{~cm}(<3 \mathrm{SD})$, and OFC $43 \mathrm{~cm}(<3 \mathrm{SD})$. The child had mild hypotonia and was unable to sit up unaided. Psychomotor development was delayed with speech impairment. The child functioned at a 10 month level at 18 months of age. No visual or auditory abnormality was observed. She had minor dysmorphic features (fig 1), including an asymmetrical face, a narrow and prominent forehead, hypertelorism, and epicanthic folds (inner canthal distance $32 \mathrm{~mm}$ ( $>97$ centile) and interpupillary distance $55 \mathrm{~mm}$ ( $>97$ centile)). The nose was short, with an abnormally broad nasal bridge and anteverted nares, the philtrum was long and flat, and the upper lip was prominent. The ears were posteriorly rotated but otherwise normal. Both hands showed tapering of the fingers and clinodactyly. As the parents were unwilling to take care of the child, she was admitted to a centre for mentally retarded children.

\section{CYTOGENETIC ANALYSIS}

Peripheral lymphocyte and fibroblast cultures were set up. Harvesting and metaphase
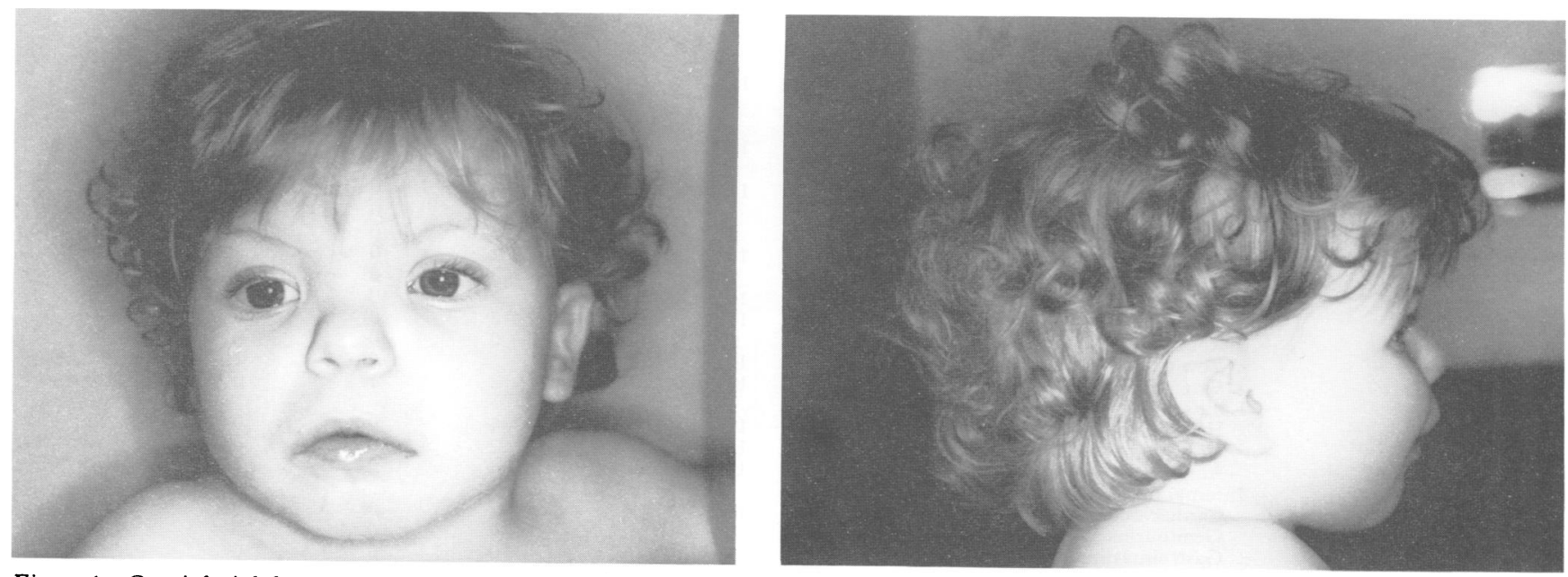

Figure 1 Craniofacial dysmorphism of the proband at 18 months. 


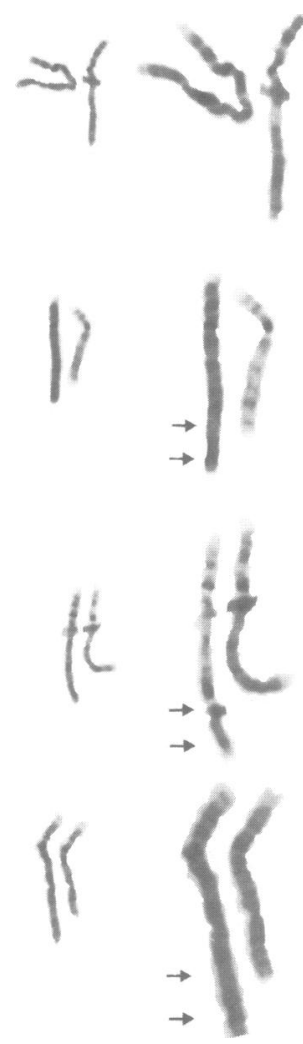

Figure 2 Partial karyotype of the patient (after high resolution $G$ banding) showing the interstitial deletion with breakpoints assigned to $4 q 31.22$ and $4 q 34.2$.

spreads were prepared by standard procedures. RHG banding studies in both tissues showed an interstitial deletion of the long arm of chromosome 4.

Subsequent high resolution $\mathrm{G}$ banding on lymphocytes assigned breakpoints to $4 \mathrm{q} 31.22$ and 4q34.2 (fig 2). The proband's karyotype is $46, \mathrm{XX}, \operatorname{del}(4)(\mathrm{q} 31.22 \rightarrow \mathrm{q} 34.2)$. The parents were not available for study. A cell line is being established.

\section{Discussion}

To the best of our knowledge no interstitial deletion of chromosome 4 with breakpoints at $\mathrm{q} 31.22 \rightarrow \mathrm{q} 34.2$ has been reported before. Terminal deletions of the long arm of chromosome 4 have been described frequently and a relatively constant phenotype can be recognised in $\operatorname{del}(4)(\mathrm{q} 31 \rightarrow \mathrm{qter})$. The salient features are craniofacial dysmorphism including hypertelorism, a short, upturned nose, a depressed nasal bridge, cleft palate with or without PierreRobin sequence, micrognathia, and external ear abnormalities. ${ }^{34}$

Other major physical findings include abnormalities of the fingers (absent digits, clinodactyly, camptodactyly, abnormal thumb or hallux implantation, tapering fingers, pointed or duplicated fifth nail), abnormal palmar creases, congenital heart defects, and genitourinary malformations. Progress is marked by postnatal growth failure and moderate or severe mental retardation. The loss of the terminal segment $4 \mathrm{q} 34 \rightarrow$ qter seems to have little clinical impact. The unique report of $\operatorname{del}(4)(\mathrm{q} 34 \rightarrow \mathrm{qter})$ by Lin et $a l^{3}$ describes the case of a 23 year old male patient with only very little facial dysmorphism and mild mental retardation. The major physical features of terminal deletions are summarised in the table.

Most interstitial deletions of the long arm of chromosome 4 involve the $\mathrm{q} 11 \rightarrow \mathrm{q} 31$ region; few cases involving q31 or more distal segments have been reported. A review of published reports showed two cases of interstitial deletion involving a common segment with our case. The first report was a case of $\operatorname{del}(4)$ $(\mathrm{q} 24 \rightarrow \mathrm{q} 32) .^{1}$ There were very few clinical features that were common to this case and the present case, only psychomotor retardation, slight dysmorphic features, and a urinary defect. The second report ${ }^{2}$ concerned del(4) $(\mathrm{q} 33 \rightarrow \mathrm{q} 35.1)$ in a mother and her two children, who had very mild craniofacial dysmorphism (long philtrum, thin upper lip, and

Distal deletion of the long arm of chromosome 4: comparison of the breakpoints in previous reports and in the present patient.

\begin{tabular}{|c|c|c|c|c|c|c|}
\hline \multirow{4}{*}{$\begin{array}{l}\text { Breakpoints } \\
\text { No of cases } \\
\text { Clinical characteristics } \\
\text { General }\end{array}$} & \multicolumn{5}{|c|}{ Previous cases } & \multirow{3}{*}{$\begin{array}{c}\text { Present case } \\
\begin{array}{c}\mathrm{q} 31.22-\mathrm{q} 34.2 \\
1\end{array}\end{array}$} \\
\hline & $\begin{array}{c}\text { q31-qter } \\
19\end{array}$ & 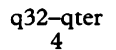 & $\begin{array}{c}\text { q33-qter } \\
6\end{array}$ & q34-qter & q33-q35.1 & \\
\hline & & & & & & \\
\hline & & & & & & \\
\hline IUGR & 3 & 1 & 0 & 0 & 0 & 0 \\
\hline Postnatal growth retardation & 15 & 2 & 5 & 0 & 0 & 1 \\
\hline Death before 2 years & 9 & 1 & 0 & 0 & 0 & 0 \\
\hline Mental retardation (if survival $>3$ months) & 11 & 4 & 4 & 1 & 3 & 1 \\
\hline Seizures & 4 & 0 & 1 & 0 & 0 & 0 \\
\hline \multicolumn{7}{|l|}{ Craniofacial } \\
\hline Abnormal skull & 12 & 3 & 4 & 0 & 0 & 1 \\
\hline Asymmetrical face & 3 & 1 & 1 & 0 & 0 & 1 \\
\hline Hypertelorism & 11 & 2 & 3 & 0 & 0 & 1 \\
\hline Epicanthic folds & 7 & 0 & 3 & 0 & 0 & 1 \\
\hline Upward slanting palpebral fissures & 4 & 0 & 3 & 0 & 1 & 0 \\
\hline Short nose & 18 & 2 & 2 & 0 & 0 & 1 \\
\hline Anteverted nares & 7 & 2 & 3 & 0 & 1 & 1 \\
\hline Depressed nasal bridge & 18 & 3 & 2 & 0 & 0 & i \\
\hline Cleft palate/lip & 17 & 4 & 2 & 0 & 0 & 0 \\
\hline Robin sequence & 5 & 4 & 0 & 0 & 0 & 0 \\
\hline Low or posteriorly rotated ears & 10 & 3 & 1 & 0 & 1 & 1 \\
\hline External ear abnormality & 13 & 3 & 2 & 1 & 0 & 0 \\
\hline \multicolumn{7}{|l|}{ Limbs } \\
\hline Hand malformations & 17 & 4 & 4 & 0 & 0 & 1 \\
\hline Transverse palmar crease & 13 & 1 & 2 & 0 & 0 & 0 \\
\hline Abnormal toes & 13 & 3 & 4 & 0 & 1 & 0 \\
\hline \multicolumn{7}{|l|}{ Internal malformations } \\
\hline Cardiac defect & 11 & 3 & 2 & 0 & 0 & 1 \\
\hline Genitourinary defect & 9 & 1 & 2 & 0 & 0 & 1 \\
\hline Gastrointestinal defect & 4 & 0 & 0 & 0 & 0 & 0 \\
\hline Bone abnormalities & 0 & 0 & 0 & 0 & 0 & 1 \\
\hline
\end{tabular}


borderline low set, posteriorly rotated ears) and moderate mental retardation.

The comparison of the features of the different deletions (terminal and interstitial) in the table shows that the phenotype of our patient is more closely related to that of patients with terminal deletions of $4 \mathrm{q} 31 \rightarrow$ qter (congenital heart defects, genitourinary defects, moderate mental retardation, postnatal growth failure, and craniofacial dysmorphism). Certain features noted in the proband, such as postnatal growth failure, psychomotor developmental retardation, and some dysmorphic traits (in particular the smooth philtrum and short nose) may be related to maternal alcohol abuse. These abnormalities are common in fetal alcohol syndrome and in chromosome 4 deletions including the segment $\mathrm{q} 31.22 \rightarrow \mathrm{q} 34.2$ and it is therefore impossible to attribute these features to one or the other of these aetiologies. It seems likely that both the chromosome abnormality and maternal alcohol abuse contributed to the clinical findings.

Monosomy of the segments $\mathrm{q} 33 \rightarrow \mathrm{q} 35.1$ and $\mathrm{q} 34 \rightarrow \mathrm{qter}$ seems to be characterised by only mild to moderate mental retardation and minor dysmorphism, without visceral defects. It would thus appear, as supported by our observation, that the characteristic phenotype attributed to terminal deletion $4 \mathrm{q} 31 \rightarrow$ qter probably mainly results from loss of the segment q31 $\rightarrow$ q33-34.

\section{Note added in proof}

The gene involved in FSH muscular dystrophy has been assigned to the segment $4 \mathrm{q} 31 \rightarrow$ qter. No clinical signs of this muscle disease were noted in our patient at the age of 18 months.

1 Serville F, Broustet A. Pericentric inversion and partial monosomy $4 \mathrm{q}$ associated with congenital anomalies. Hum Genet 1977;39:239-42.

2 Curtis MA, Smith RA, Sibert JO, et al. Interstitial deletion, $\operatorname{del}(4)(\mathrm{q} 33 \mathrm{q} 35.1)$, in a mother and two children. $\mathcal{f} \mathrm{Med}$ Genet 1989;26:652-4.

3 Lin AE, Garver KL, Diggans G, et al. Interstitial and terminal deletions of the long arm of chromosome 4 further delineation of phenotypes. Am $\mathcal{f}$ Med Gene 1988;31:533-48.

4 De Michelena MI, Campos PJ. Terminal deletion $4 \mathrm{q}$ in a severely retarded boy. Am F Med Genet 1989;33:228-30. 